\title{
Chemical fluxes and mass balances in a marine fish cage farm. IV. Nitrogen
}

\author{
Per O. J. Hall ${ }^{1}$, Ola Holby ${ }^{1}$, Sven Kollberg ${ }^{2}$, Matts-Ola Samuelsson ${ }^{3}$ \\ ${ }^{1}$ Department of Analytical and Marine Chemistry, University of Göteborg and Chalmers University of Technology, \\ S-41296 Göteborg, Sweden \\ ${ }^{2}$ Länsmansvägen 4, S-45052 Dingle, Sweden \\ ${ }^{3}$ Swedish Environmental Research Institute (IVL), Box 21060, S-10031 Stockholm, Sweden
}

\begin{abstract}
Fluxes of nitrogen in a trout cage farm in open coastal water of the Gullmar Fjord, western Sweden, were measured to examine and describe the fate and major pathways of nitrogen supplied to the farm. The flux measurements included sedimentation from the cages, and sediment-water solute exchange measured with flux chambers operated by divers in situ. Benthic flux chambers were also utilized to measure denitrification rates in the sediment using the acetylene inhibition technique in situ. The nitrogen input to the farm with fish food and juveniles, and the removal through harvest and fish loss (death and escape) were also quantified. Two approaches were used to construct nitrogen mass balances for the farm. One (the flux method) was based on the measured fluxes and constructed for each of 2 consecutive cultivation seasons. The other (the accumulation method) was based on the total nitrogen input with food and juveniles to the farm since it was started, the removal of nitrogen with harvested fish and fish loss, and the recovery of nitrogen in the farm-derived sediment after 7 cultivation seasons. Of total nitrogen input to the farm, 27 to $28 \%$ was recovered in harvest, fish loss constituted 2 to $5 \%$, and 67 to $71 \%$ (or 95 to $102 \mathrm{~kg} \mathrm{~N}$ per tonne produced fish) was lost to the aquatic environment. Of the nitrogen input to the farm and on a seasonal basis, solute release from the cages (presumably mostly excreted urea and ammonia) removed $48 \%$, particle sedimentation (excess feed and faeces) constituted $23 \%$, benthic nitrogen net flux [dissolved organic nitrogen (DON), ammonium, nitrate, urea and denitrification products] transferred 1 to $3 \%$ back to the water column, and $20 \%$ was accumulated in the sediment. On a longer time-scale ( 7 seasons), sediment nitrogen accumulation amounted to $12 \%$ of the nitrogen input to the farm. A net fraction of $11 \%$ of the nitrogen input to the farm sediment was released back in dissolved form to the overlying water on a seasonal basis. DON dominated the seasonal benthic flux. Denitrification constituted a very minor pathway for the transfer of nitrogen from the farm sediment to the water column (and ultimately to the atmosphere). The benthic flux removed seasonally 1.2 to $3.8 \%$ of the nitrogen present in the farm-derived sediment. Loss to the environment of dissolved nitrogen (the sum of benthic flux and solute release from the cages) amounted to $51 \%$ of the nitrogen input to the farm (or $72 \%$ of the total environmental loss) on a seasonal basis, and $58 \%$ (or $83 \%$ of the total environmental loss) on a long-term basis. In this last paper in the series on the fish farm, the input and fate of carbon, phosphorus and silicon are compared with those of nitrogen.
\end{abstract}

\section{INTRODUCTION}

Cage fish farming is expanding in many parts of the world. Threats to the development of this industry include the occurence of toxic algal blooms, transmission of diseases, and possible impact on the environment caused by the farming activity such as dispersion of organic matter and nutrients to surrounding waters. How much of the nutrients, added to the farm with fish food, is lost to the environment? How much of the environmental loss is in particulate and in dissolved forms? Are particles sinking from the fish cages to the bottom permanently buried in the sediment, or are they degraded and released back in dissolved form to the water column? These questions have to be addressed before decisions on the density of fish farming in open waters can be made.

It appears from recent overviews on the environmental impact of fish cage farming (Ackefors 1986 , Gowen \& Bradbury 1987, Persson 1987, Håkanson et al. 1988, Rosenthal et al. 1988, Folke \& Kautsky 1989, Ackefors \& Enell 1990) that there is a great need for 
direct measurements of material fluxes in cage farms including sedimentary processes.

Carbon, phosphorus and silicon fluxes have been measured and mass balances constructed for a marine trout cage farm in the Gullmar Fjord, western Sweden (Hall et al. 1990, Holby \& Hall 1991, unpubl.). The aim of this paper is to present nitrogen fluxes and mass balances for the farm, and to describe the fate and major pathways of nitrogen supplied to the farm. We show how much of the nitrogen, put in with fish food and juveniles, is recovered in harvested fish, how much is lost to the environment, how much of the environmental loss appears in particulate and in dissolved form, how much is returned in dissolved form from the sediment to the overlying water, and how much is accumulated in the sediment.

\section{MATERIALS AND METHODS}

Farm site. The fish cage farm is situated in coastal marine water of the Gullmar Fjord, western Sweden. The farm was established in 1980. Rainbow trout Oncorhynchus mykiss is the cultivated species. At most 15 net cages have been used in the farm, but the number of cages utilized has varied annually. During 1985 there were 5 cages in use from the start of the growing season (beginning of May) until mid-July, when the growing fish were redistributed into 8 cages. This number of cages was used until the end of season (end of January). The corresponding number of cages during the 1986 season was 4 (beginning of May to mid-June) and 7 (until mid-January).

The water at the farm site is stratified with a surface water salinity of typically 20 to $25 \mathrm{PSU}$ and a bottom water salinity of 30 to 35 PSU. The bottom depth at the site is 18 to $21 \mathrm{~m}$. Water circulation in the farm area is sufficient to keep the bottom water well-oxygenated throughout the year.

The top layer of sediment below the cages is strongly influenced by the farm. This layer is extremely organic-rich, very reducing and highly sulfidic. It is completely black, has a very high water content and during part of the year is covered by a white bacterial mat. Underlying the top sediment layer is a light brown, more compacted sediment. Gas ebullition takes place in the sediment during late summer and fall.

Nitrogen in fish and fish food. The nitrogen content of whole rainbow trout as a function of fresh weight was calculated according to Persson (1986), who gave the following relation

$$
\% N=0.096 \times 17.4 \times W^{0.099}
$$

where $W$ is the fresh weight in $g$
Each of the various foods used in the farm was homogenized into fine particles and the water content determined from the weight loss at $105^{\circ} \mathrm{C}$ after drying for at least $24 \mathrm{~h}$. The dried food samples were analyzed for nitrogen on a Carlo Erba CHN elemental analyzer model 1106

Sedimentation fluxes. Cylindrical sediment traps with a diameter of $8 \mathrm{~cm}$ and an aspect ratio of 6.2 were used to collect sinking particles from the cages. Traps were positioned ca $10 \mathrm{~m}$ below the bottom of the cages (i.e. $6 \mathrm{~m}$ above the bottom). Sedimentation rates were also on 1 occasion measured at a site $200 \mathrm{~m}$ outside the farm. Three traps were used on each occasion. Sampling times were 24 to $48 \mathrm{~h}$. After collection, the particles in each trap were immediately suspended in 21 of bottom water from the site. Three aliquots from each of the homogenized suspensions were filtered through precombusted Whatman GF/F glass microfibre filters. The filters were analyzed for particulate nitrogen on a Carlo Erba CHN elemental analyzer model 1106 using blank filters as a control.

Benthic in situ fluxes. Sediment-water exchange of nitrate, DON, ammonium and urea was measured in situ below the cages with benthic flux chambers. The chambers (ca 118 I of water over $0.20 \mathrm{~m}^{2}$ of sediment surface area) were made of $70 \mathrm{~cm}$ long $\times 50 \mathrm{~cm}$ diameter Plexiglas tube. They were carefully placed by Scuba divers at least $10 \mathrm{~cm}$ into the sediment. The exact height of water column in the individual chambers was measured during each experiment, and the corresponding chamber volume used when calculating the benthic fluxes. Chambers were equipped with a $7.5 \mathrm{~cm}$ long, $0.8 \mathrm{~cm}$ diameter, Teflon-coated magnetic stirring bar revolving at $75 \mathrm{rpm}$, Teflon valves for sampling, and a flexible membrane consisting of several layers of polyethylene bag that served to compensate the volume removed during sampling. Some of the chambers in each experiment ('regulated chambers') were also equipped with a coil of Teflon tubing through which oxygen gas, supplied under pressure from the surface, could diffuse into the chambers. In these chambers dissolved oxygen was kept close to the original value throughout the experiments by adjusting the pressure in the oxygen supply tubing. The 'unregulated chambers', which were not supplied with oxygen, were allowed to run anoxic as a result of benthic oxygen consumption processes. Benthic chambers may interfere with the natural circumstances at the sediment-water interface, e.g. by eliminating the supply of organic matter to the sediment and by disturbing the flow regime. When constant fluxes are measured (i.e. there is no lack of reactive organic matter and no interference from the increase in concentration of the released substance) in regulated chambers, the main task when measurements are conducted in the coastal 
environment is to adjust stirring rates to actual in situ hydrodynamic conditions (Hall 1984). This task is not trivial and is seldom completely fulfilled. However, benthic chambers are the best technique available for the study of several exchange processes (Santschi et al. 1990)

Chamber experiments were carried out for 16 to $24 \mathrm{~d}$ in December 1984, May 1985, September 1985 and July 1986. Bottom water temperatures during the experiments ranged from 4 to $16^{\circ} \mathrm{C}$. Two to five chambers were used during each experiment.

Samples from the chambers were normally taken once per day by divers with polypropylene syringes. All samples were stored filtered $(0.45 \mu \mathrm{m}$ Millipore) and frozen in plastic bottles until analysis at the end of each experiment. Nitrate and nitrite were determined according to Anderson (1979), total dissolved nitrogen (TDN) using the persulfate oxidation method of Valderrama (1981), ammonium following a modified Solorzano (1969) method, and urea according to Newell et al. (1967). DON was calculated as the difference between TDN and the sum of nitrate, nitrite and ammonium (i.e. all DON values reported here include urea).

Denitrification. The acetylene inhibition technique (Sørensen 1978a) was utilized in situ to measure denitrification rates in the sediment using smaller versions of regulated flux chambers (containing 101 of water over $0.033 \mathrm{~m}^{2}$ of sediment surface area). Nitrate and ammonium fluxes were also measured in these chambers, which were run in parallel with the large chambers. Acetylene saturated seawater, having the same density as the water of the denitrification chambers, was injected into each chamber so that the initial acetylene concentration in them was $5 \%$ of saturation. A saturation of $0.7 \%$ has been shown to inhibit nitrous oxide reduction (Sørensen 1978b). Injections took place daily during the September 1985 and July 1986 experiments, and twice (on Days 8 and 14) during the May 1985 experiment. The actual concentration of acetylene in the chambers was determined throughout the former experiments, but not during May 1985.

Samples from the chambers for nitrous oxide were collected in glass syringes and transferred to glass bottles of known volume. Saturated $\mathrm{HgCl}_{2}$ solution $(0.8 \mathrm{ml})$ was added to $100 \mathrm{ml}$ of sample to prevent further biological activity. The glass bottles were sealed with rubber stoppers and stored at $4{ }^{\circ} \mathrm{C}$ until analysis. Dissolved nitrous oxide was determined according to Rönner (1983) and Samuelsson (1986) on a Packard 487 gas chromatograph furnished with an electron capture detector $\left(320^{\circ} \mathrm{C}, 10 \mathrm{mV}\right)$ using a head-space technique. The column (oven temperature $\left.50^{\circ} \mathrm{C}\right)$ was packed with Porapak Q (100/80 mesh), and the carrier was a mixture of $90 \%$ Ar and $10 \% \mathrm{CH}_{4}$.

Sediment and pore water. Sediment cores were taken below the cages, as well as at a distance of $20 \mathrm{~m}$ outside the farm (where no farm-derived sediment was observed), by divers in September 1984. Cores were also collected below the cages in May 1985 and July 1986. The cores were extruded under nitrogen in a glove box. Pore water samples were obtained by centrifugation and filtration, and analyzed for ammonium by the analytical procedure above after hydrogen sulfide had been removed by acidification and nitrogen bubbling. Concentrations of nitrogen in dried sediment samples were measured on a Carlo Erba CHN elemental analyzer model 1106

Estimation of the volume of farm-derived sediment. The mass balance constructed according to the accumulation method (see below) was based on (among other parameters) the recovery of nitrogen in the sediment after 7 growing seasons. To calculate this recovery, the volume of sediment originating from the farm had to be estimated. The procedures for this estimation have been presented elsewhere (Hall et al. 1990, Holby \& Hall 1991). Briefly, the areal distribution of farm sediment was estimated by divers using the black and loose appearence as indicators of this sediment; the vertical sedimentary phosphorus distribution was used as indicator of the thickness of the sediment layer derived from the farm.

Assumptions for constructing mass balances. The assumptions made to calculate the total seasonal sedimentation and the total seasonal benthic flux in the farm have been given in Holby \& Hall (1991). The sedimentation rate of nitrogen mesured in November 1985 was assumed to be constant until the end of that season. Benthic fluxes in December 1985 were assumed to be equal to the fluxes measured in December 1984 and to be valid until the end of the 1985 season. Benthic DON fluxes were not measured in December 1984 or in September 1985, but were assumed during these periods to be equal to the mean of all available DON fluxes. The mean of all measured denitrification rates was used for December 1984, when no denitrification measurements were carried out. Benthic nitrogen fluxes during the 1986 season were measured in July and estimated for the other months assuming that the annual variation of each flux observed during 1985 was valid also during 1986.

\section{RESULTS}

The nitrogen concentration of the various fish foods (which were of the dry food type; Table 1) was within the range 6.6 to $9.4 \%$ (dry $w / w$ ), and the water content 
Table 1. Input data, measured nitrogen concentrations and water contents of the various fish foods used in the farm during 1985 , 1986 and 1980 to 1986

\begin{tabular}{|c|c|c|c|c|c|}
\hline \multirow[t]{2}{*}{ Brand name } & \multicolumn{3}{|c|}{ Input $(\mathrm{kg} \text { wet } \mathrm{wt})^{d}$} & \multirow{2}{*}{$\begin{array}{l}\text { Nitrogen concentration } \\
\qquad \%(d r y w / w)\end{array}$} & \multirow{2}{*}{$\begin{array}{l}\text { Water content } \\
\%(\text { wet } w / w)\end{array}$} \\
\hline & 1985 & 1986 & $1980-86$ & & \\
\hline EWOS T51 & 34000 & 8900 & 178200 & $6.68-7.01^{\mathrm{b}}$ & $6.7-7.9^{b}$ \\
\hline EWOS ET92 & - & 5700 & 5700 & 6.64 & $3.2^{c}$ \\
\hline EWOS T45 & - & - & 4200 & $7.57^{d}$ & $7.4^{d}$ \\
\hline Danish Ørred (Ecolife 16) & - & 3750 & 3750 & 7.69 & 8.4 \\
\hline Aller Mølle AT67 & - & - & 500 & 9.42 & 8.2 \\
\hline Aller Mølle 46/19 & - & - & 7000 & 7.99 & 10.0 \\
\hline Total input & 34000 & 18350 & 199350 & - & - \\
\hline \multicolumn{6}{|l|}{ a Data given by fish farmer } \\
\hline \multirow{2}{*}{\multicolumn{6}{|c|}{$\begin{array}{l}\text { Samples from } 2 \text { batches analyzed. One batch was analyzed from each of the other foods } \\
\text { This value appears low }\end{array}$}} \\
\hline & & & & & \\
\hline \multicolumn{6}{|c|}{$\begin{array}{l}\text { Samples of this food were not available. The mean of the nitrogen concentrations and water contents, respectively, of the } \\
\text { other } 6 \text { food batches analyzed was used }\end{array}$} \\
\hline
\end{tabular}

6.7 to $10.0 \%$ (wet $w / w$ ). The input of nitrogen with fish food to the farm was calculated from food input data (Table 1) and the nitrogen content of food.

The nitrogen supply to the farm with addition of juveniles and the removal through harvest and fish loss (death and escape of fish) were calculated from fish data given by the fish farmer and the calculated nitrogen concentrations of whole rainbow trout (Table 2).

The measured nitrogen sedimentation rates, and benthic fluxes of nitrate, DON, ammonium, urea and nitrous oxide (used as a measure of denitrification in acetylene inhibited chambers) are presented in Table 3. No ben-

Table 2. Oncorhynchus mykiss. Juvenile input, harvest, fish loss (death and escape) and nitrogen concentrations of rainbow trout in the farm during 1985, 1986 and 1980 to 1986

\begin{tabular}{|c|c|c|c|}
\hline Year & $\begin{array}{c}\text { Weight } \\
(\mathrm{kg} \text { fresh wt })^{d}\end{array}$ & $\begin{array}{c}\text { Size } \\
\text { (g fresh wt) }\end{array}$ & $\begin{array}{l}\text { Nitrogen conc. } \\
\%(\text { fresh } w / w)\end{array}$ \\
\hline \multicolumn{4}{|l|}{ Juveniles } \\
\hline 1985 & 3700 & $160-380^{\mathrm{d}}$ & $2.76-3.01$ \\
\hline 1986 & 3200 & $160-450^{\prime \prime}$ & $2.76-3.06$ \\
\hline $1980-86$ & 26340 & $100-1000^{\mathrm{a}}$ & $2.64-3.31$ \\
\hline \multicolumn{4}{|l|}{ Harvest } \\
\hline 1985 & 18300 & $1160^{c}$ & 3.36 \\
\hline 1986 & 10500 & $1290^{c}$ & 3.40 \\
\hline $1980-86$ & 109140 & $1320^{c}$ & 3.40 \\
\hline \multicolumn{4}{|l|}{ Fish loss } \\
\hline 1985 & 1230 & $700^{d}$ & 3.20 \\
\hline 1986 & 1880 & $820^{d}$ & 3.25 \\
\hline $1980-86$ & 10900 & $860^{\circ}$ & 3.26 \\
\hline \multicolumn{4}{|c|}{ a Data given by fish farmer } \\
\hline \multicolumn{4}{|c|}{$\begin{array}{l}\text { b Calculated for whole rainbow trout according to Persson } \\
\text { (1986) } \\
\text { "Average size calculated from the weight of harvest, and } \\
\text { the no. of fish remaining in the farm at the end of season } \\
\text { after any fish loss } \\
\text { d Estimated as half of the average size of produced fish }\end{array}$} \\
\hline
\end{tabular}

thic nitrite fluxes (neither uptake nor release) were observed. The presented benthic fluxes are initial fluxes or, for $\mathrm{N}_{2} \mathrm{O}$, those measured after acetylene injection. Examples of the evolution of nitrogen compounds in regulated and unregulated chambers are shown in Figs, 1 to 4 . Oxygen was consumed within 1 to $2 \mathrm{~d}$ in the unregulated chambers during all experiments. Nitrate fluxes were always directed from the overlying water into the sediment. In the unregulated chambers, however, we were not able to measure any nitrate fluxes, because nitrate was detected only on first day of incubation or not at all (Table 3). No systematic difference between DON and urea fluxes was measured in the regulated and unregulated chambers. Ammonium fluxes were always considerably higher in anoxic chambers than in oxygenated ones. Fluxes of nitrous oxide were only measured in regulated chambers. During the September 1985 and July 1986 experiments, the acetylene concentration in the denitrification chambers was almost constant at a level of 5 to $7 \%$ of saturation throughout the experiments. During these experiments the concentration of nitrous oxide increased throughout the whole chamber incubation. During May 1985, when acetylene was not injected on a daily basis, there was an initial increase in the nitrous oxide flux after acetylene injection, followed by a consumption of nitrous oxide (Fig. 4). Fluxes of $\mathrm{N}_{2} \mathrm{O}$ were very minor compared to most other nitrogen fluxes. Gas bubbles, that were released from the sediment during late summer and fall, were collected and analyzed for $\mathrm{N}_{2} \mathrm{O}$, but no trace of this substance could be detected. The gas bubbles consisted almost entirely of methane (Hall et al. 1990).

The sediment below the cages was very rich in nitrogen. Examples of the sedimentary nitrogen distribution are shown in Fig. 5. The nitrogen concentration was 1.9 to $2.1 \%$ (dry wt) in the uppermost $2 \mathrm{~cm}$ of farm sediment. 
Table 3. Measured sedimentation rates and benthic fluxes of nitrogen (mmol $\mathrm{N} \mathrm{m}^{-2} \mathrm{~d}^{-1}$ ) under the farm during 1984,1985 and 1986. reg.: Oxygen conc. maintained close to original value; unreg.: chamber allowed to run anoxic due to benthic oxygen consumption. Negative values denote benthic fluxes into the sediment.

\begin{tabular}{|c|c|c|c|c|c|c|}
\hline \multirow[t]{2}{*}{ Period } & \multirow[t]{2}{*}{ Sedimentation } & \multicolumn{5}{|c|}{ Benthic fluxes } \\
\hline & & DON & $\mathrm{NH}_{4}$ & $\mathrm{NO}_{3}$ & Urea & Denitrification " \\
\hline Dec 1984 & - & $14.94^{b}$ & & & & $9.85 \times 10^{-3^{b}}$ \\
\hline Chamber A (unreg.) & - & - & $0.202^{\mathrm{C}}$ & d & 0 & - \\
\hline Chamber B (reg.) & - & - & 0.336 & d & 0 & - \\
\hline May 1985 & $136.3^{e}$ & & & & & - \\
\hline Chamber A (unreg.) & - & - & 1.969 & d & -0.834 & - \\
\hline Chamber 1 (unreg.) & - & 24.60 & 2.303 & d & -0.388 & - \\
\hline Chamber B (reg.) & - & 25.86 & 0 & -0.765 & -0.195 & - \\
\hline Chamber 2 (reg.) & - & - & 0 & -0.393 & -0.055 & - \\
\hline Chamber 3 (reg.) & - & - & 0 & -0.552 & - & $2.70 \times 10^{-3}$ \\
\hline Jun 1985 & $309.7^{e}$ & - & - & - & - & - \\
\hline Sep 1985 & $295.7^{\mathrm{e}}$ & $14.94^{\mathrm{b}}$ & & & & \\
\hline Chamber 1 (unreg.) & - & - & 28.66 & d & 1.860 & - \\
\hline Chamber 2 ('reg.') & - & - & $26.29^{1}$ & $d, f$ & - & - \\
\hline Chamber B (reg.) & - & - & 1.202 & -0.334 & 0.226 & - \\
\hline Chamber 3 (reg.) & - & - & 1.117 & -0.226 & - & $26.3 \times 10^{-3}$ \\
\hline Oct 1985 & $283.3^{\mathrm{e}}$ & - & - & - & - & - \\
\hline Nov 1985 & $15.08^{e}$ & - & - & - & - & - \\
\hline Jul 1986 & - & & & & & \\
\hline Chamber A (unreg.) & - & 5.397 & 6.879 & d & 0.473 & - \\
\hline Chamber 2 (reg.) & - & 3.912 & 3.061 & -0.381 & 0 & - \\
\hline Chamber C (reg.) & - & - & - & - & - & $0.55 \times 10^{-3}$ \\
\hline $\begin{array}{l}{ }^{a} \text { Measured as the flux } \\
\text { b Value estimated for th } \\
\text { c Flux represents initial } \\
\text { d Flux not measurable } \\
\text { e Value represents the } \\
\text { ' Chamber turned anox }\end{array}$ & $\begin{array}{l}\mathrm{J}_{2} \mathrm{O} \text { in acetylene- } \\
\text { oeriod (see text) } \\
\text { c phase of incub } \\
\text { an of } 9 \text { subsample } \\
\text { fter } 4 \mathrm{~d} \text {; anoxic fl }\end{array}$ & Iuots fro & of $3 \mathrm{sed}$ & traps) & & \\
\hline
\end{tabular}

The thickness of the sediment layer derived from the farm was $18 \mathrm{~cm}$ immediately below the cages and became thinner with distance from the farm edge. Farm-derived sediment was observed over an area of $3800 \mathrm{~m}^{2}$ around and below the farm. This gave a total volume of wet farm sediment of $459 \mathrm{~m}^{3}$. The average density and water content of wet farm sediment was $1.078 \mathrm{~g} \mathrm{~cm}^{-3}$ and $82.7 \%$, respectively (Hall et al. 1990). Using these values and an average dry-weight-based nitrogen concentration in the sediment layer originating from the farm of $1.87 \%$, we obtained a net nitrogen accumulation in the farm-derived sediment of $1600 \mathrm{~kg} \mathrm{~N}$.

\section{DISCUSSION}

\section{Mass balances}

Mass balances need to be constructed in order to enable estimation of total and dissolved environmen- tal losses from fish farms, as well as sedimentary accumulation rates. We used 2 approaches when constructing nitrogen mass balances for the cage farm. The 'flux method' was based on calculations of the seasonal nitrogen fluxes carried by fish food, juveniles, harvest and fish loss, and on measurements of sedimentation and benthic fluxes of nitrogen. The 'accumulation method' was based on determinations of the total nitrogen input to the farm (since it was started) with fish food and juveniles, the removal with harvest and fish loss, and the net accumulation of nitrogen in the sediment. Mass balances according to the flux method were constructed for the growing seasons of 1985 and 1986. A long-term ( 7 yr) nitrogen balance was calculated according to the accumulation method for the consecutive growing seasons of 1980 through 1986. The mass balances were constructed for oxygenated benthic boundary conditions (which is the normal situation below the farm), i.e. only oxic benthic fluxes were used. The mass balances are presented in Fig. 6 and Table 4. Descriptions of how com- 

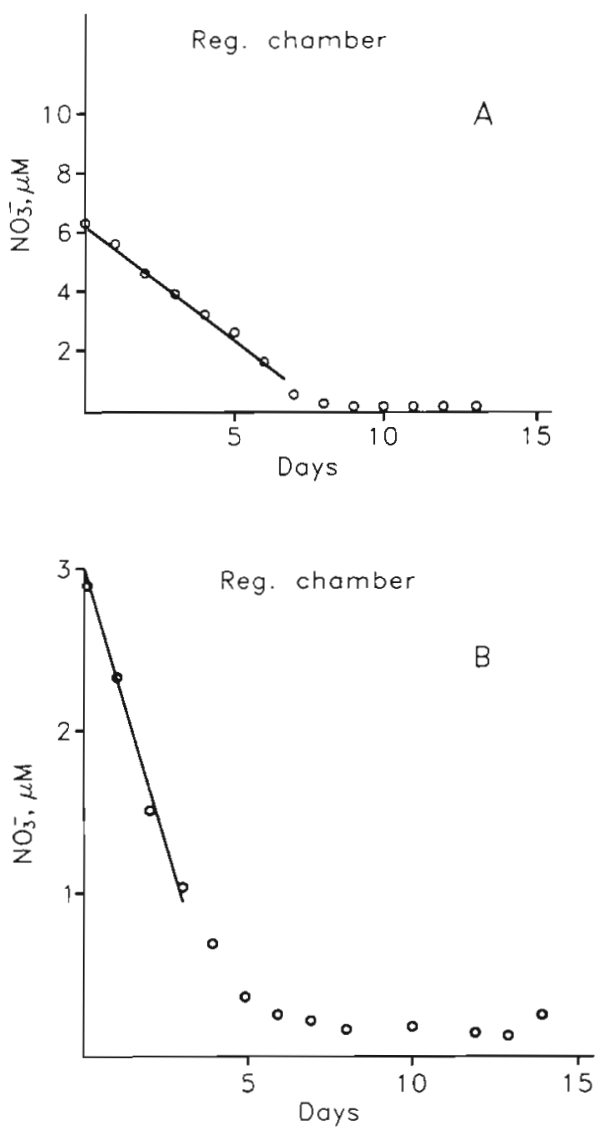

Fig. 1 Evolution of nitrate in regulated chambers during the (A) May 1985 and (B) July 1986 flux chamber experiments Note difference in scales

ponents of the mass balances were calculated have been given previously (Hall et al. 1990, Holby \& Hall 1991)

\section{Comparison of the mass balances}

The recovery in harvest of the total nitrogen input to the farm (Fig. 6A) agreed excellently in all 3 mass balances, being 27,28 and $27 \%$ during the 1985, 1986 and 1980 to 1986 seasons, respectively. The contribution of fish loss (death and escape) to the overall nitrogen cycling in the farm was relatively small during all seasons ( 2 to $5 \%$ ). Most of the nitrogen supplied to the farm was lost to the environment. The total environmental loss amounted to 102,95 and $102 \mathrm{~kg} \mathrm{~N}$ per tonne $(\mathrm{t})$ of fish produced (numbers obtained when fish loss is considered part of the fish production) during the 1985,1986 and 1980 to 1986 growing seasons, respectively. This corresponded to 71,67 and $70 \%$ of the total nitrogen input to the farm during these 3 time periods. The 3 mass balances agreed well with regard to the contribution of food (93 to $95 \%$ ), juveniles (5 to
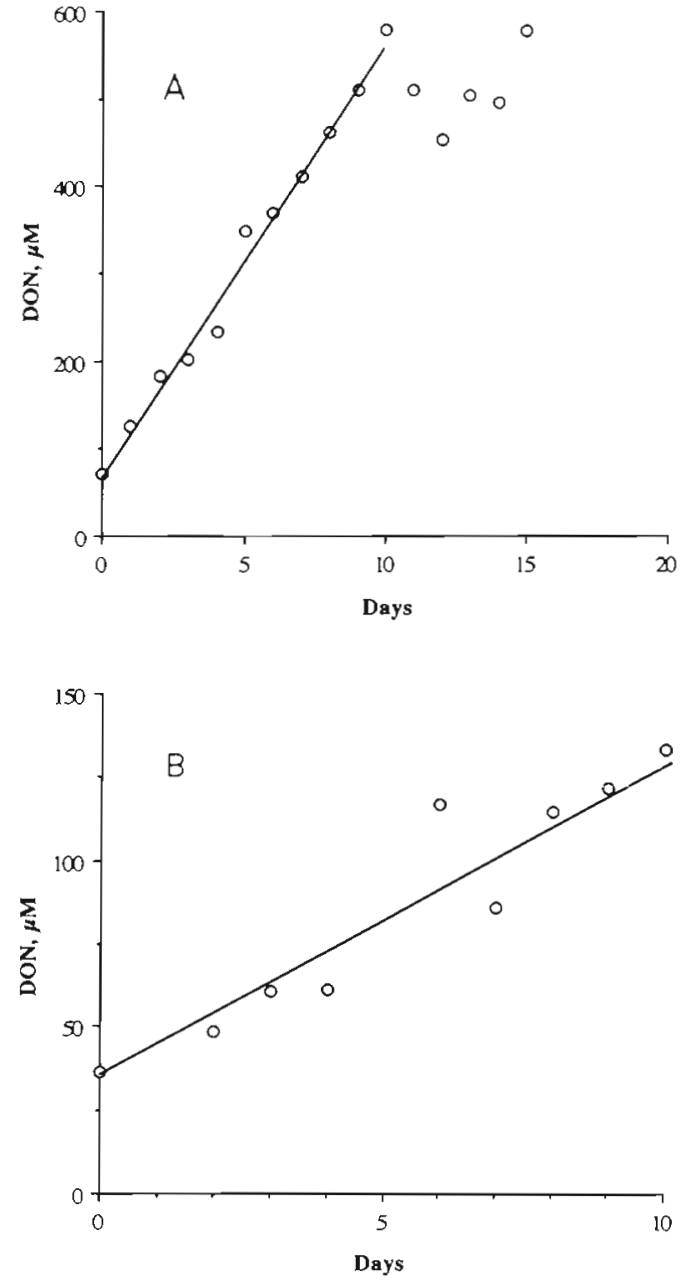

Fig. 2. Evolution of DON in regulated chambers during the (A) May 1985 and (B) July 1986 flux chamber experiments. Note difference in scales

$7 \%$ ) and harvest to the turnover of nitrogen within the cages, as well as the fractions of the nitrogen input to the farm that was recycled in the sediment (benthic flux; 1 to $3 \%$ ) and that was lost to the environment (see Fig. 6 and Table 4). The agreement between the mass balances for 1985 and 1980 to 1986 with regard to sediment accumulation ( 20 to $12 \%$ ) and dissolved environmental loss (51 to $58 \%$ ) was fair. However, the lower sediment accumulation and larger dissolved environmental loss during 1980 to 1986 compared to 1985 can be explained as a result of resuspension. In the long-term mass balance, the environmental loss that is not recovered in the sediment is defined as dissolved environmental loss. If resuspension on a longer timescale removed some particulate nitrogen from the farm sediment, that would result in the dissolved loss being larger in the long-term budget than in the seasonal one. We believe this is the reason for the discrepancies 

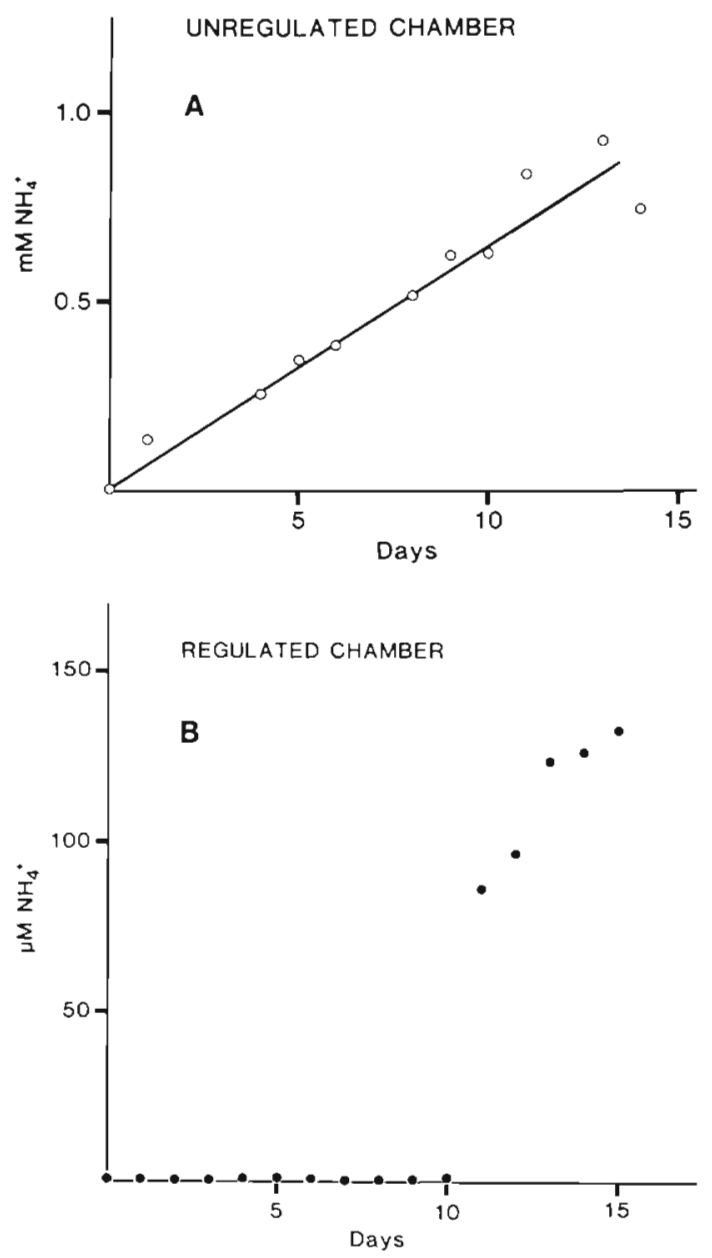

Fig. 3. Evolution of ammonium in $(A)$ an unregulated chamber during the September 1985 and (B) a regulated chamber during the May 1985 flux chamber experiment. The chamber in (B) could not be maintained regulated throughout the incubation, but turned anoxic between Days 10 and 11. Note difference in scales

in sediment accumulation and dissolved environmental loss between these periods.

\section{Comparison with previous studies}

Persson (1986) studied trout cage farms in brackish water of the Baltic Sea, and found that $72 \%$ of the nitrogen supplied with food to the farms was lost to the environment. On average $80 \%$ of the environmental loss was in dissolved and $20 \%$ in particulate form. Enell (1987) investigated fresh water cage farms and found that $74 \%$ of the nitrogen input with food constituted the environmental loss. This corresponded to $86 \mathrm{~kg} \mathrm{~N} \mathrm{t}^{-1}$ of fish produced. Of the environmental loss, $78 \%$ was in dissolved form. For trout cage farming in a freshwater loch, Phillips et al. (1985) reported an envi-

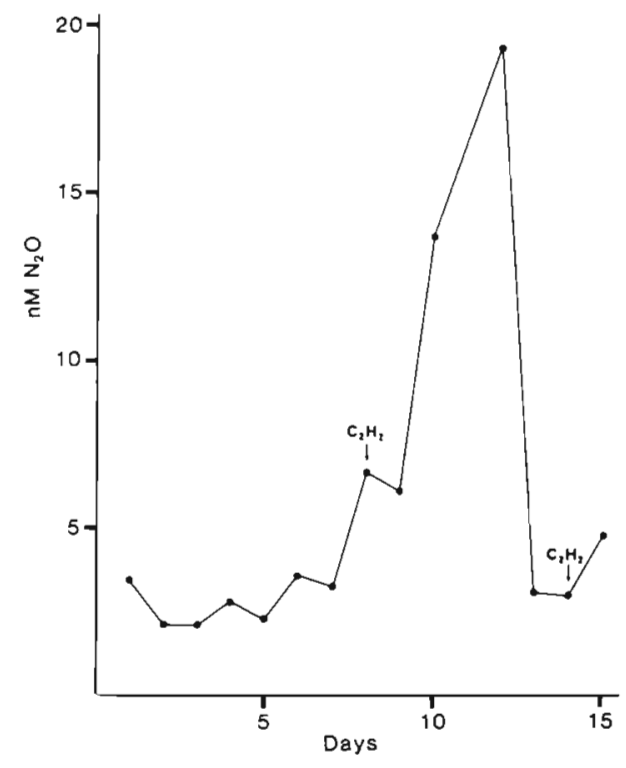

Fig. 4. Evolution of nitrous oxide in the smaller version of regulated chamber during the May 1985 flux chamber experiment. Arrows indicate injection of acetylene-saturated seawater into the chamber

ronmental nitrogen loss of $79 \%$ (or $104 \mathrm{~kg} \mathrm{~N} \mathrm{t}^{-1}$ of fish production) of the nitrogen supplied with feed. Also here, most of the waste was in soluble form. Gowen et al. (1985), based on theoretical calculations, estimated the environmental nitrogen load to be $80 \%$ of the nitrogen input with food. However, they assumed that $20 \%$ of the food input was wasted. An environmental loss of $100 \mathrm{~kg} \mathrm{~N}$ per tonne of fish produced was reported for a lake water cage farm by Penczak et al. (1982). The data above (environmental losses of 72 to $80 \%$ of nitrogen input, or 86 to $104 \mathrm{~kg} \mathrm{~N} \mathrm{t}^{-1}$ produced fish) are in good general agreement with our results ( 67 to $71 \%$, or 95 to $102 \mathrm{~kg} \mathrm{~N} \mathrm{t}^{-1}$ ). However, we also considered juvenile input and fish loss removal when calculating the environmental losses. There seems to be a good agreement between studies with regard to the composition of this loss. We, like many other studies, found the soluble fraction to dominate.

According to Molvœe \& Stigebrandt (1989), $40 \mathrm{~kg} \mathrm{~N}$ $\mathrm{t}^{-1}$ of fish production is excreted in dissolved form directly from the fish to the water. The solute release from the cages in this study, which was obtained from sedimentation measurements and mass balance calculations (Table 4), was $69 \mathrm{~kg} \mathrm{~N} \mathrm{t}^{-1}$ fish produced during 1985 (fish production $=15.8 \mathrm{t}$ including fish loss; Table 2).

The benthic flux removed seasonally 1.2 to $3.8 \%$ of the nitrogen present in the farm-derived sediment. If this is used as a measure of the annual degradation rate of farm sediment (keeping in mind that the de- 

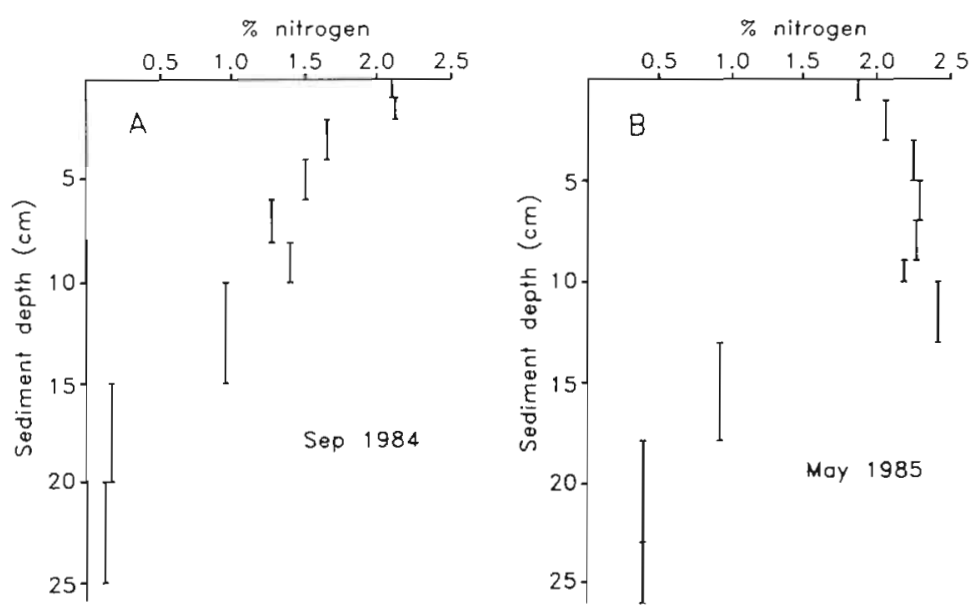

Fig 5. Concentrations of nitrogen ( $\%$ dry wt) as a function of depth in the sediment below the fish farm in (A) September 1984 and (B) May 1985 nitrufication rates were very low), then this sediment degrades slowly with regard to nitrogen compared to other farm sediments where a degradation of $10 \%$ of the organic matter in a sediment layer has been estimated per year (Aure \& Stigebrandt 1990). We obtained a corresponding degradation rate for carbon in the farm sediment of 1.2 to $5.2 \%$ (Hall et al. 1990). However, $11 \%$ of the nitrogen input to the farm sediment was released back in dissolved form to the overlying water on a seasonal basis (Fig. 6B). The corresponding number for carbon was $20 \%$, for phosphorus on average $6 \%$ (Holby \& Hall 1991) and for silicon $4 \%$ (Holby \& Hall unpubl.). Comparisons of sedimentation fluxes and benthic fluxes on a

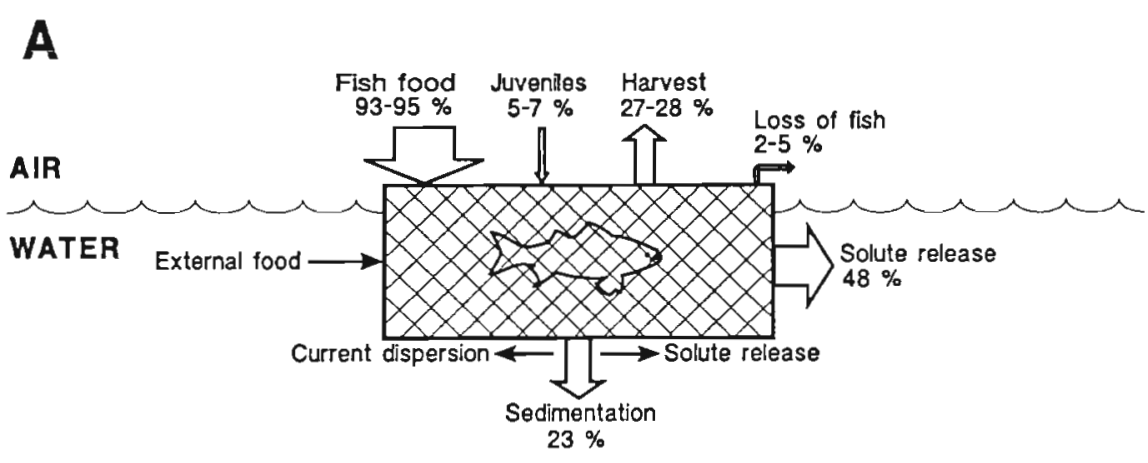

SEDIMENT

B
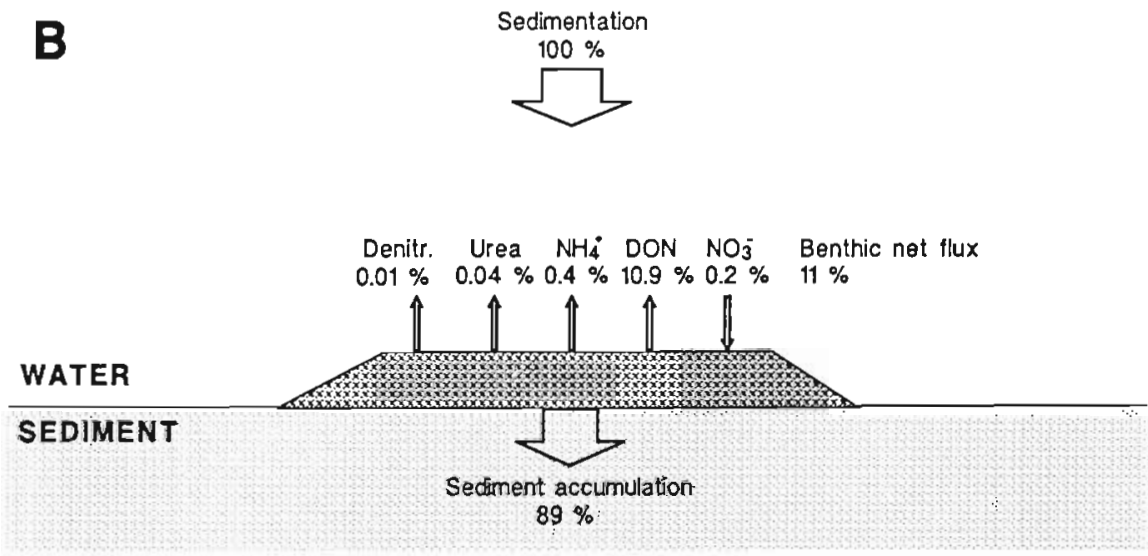

Fig. 6. Nitrogen mass balances in the cage farm constructed according to the flux and the accumulation methods. Fish loss is death and escape of fish. Unquantified arrows represent processes that constitute possible sources of error in the mass balances. Actual numbers for each mass balance are given in Table 4 (A) Percentages refer to \% of total nitrogen input to farm (the sum of fish food and juveniles). Ranges of values given represent interseasonal variability $(1985,1986$ and 1980 to 1986). (B) Percentages refer to \% of total nitrogen input to sediment for the growing season of 1985 
Table 4. Summary of the nitrogen mass balances for 1985,1986 and 1980 to 1986 . Percentages refer to \% of total N input to farm

\begin{tabular}{|c|c|c|c|c|c|c|}
\hline \multirow{2}{*}{ Components of the mass balances } & \multicolumn{2}{|c|}{1985} & \multicolumn{2}{|c|}{1986} & \multicolumn{2}{|c|}{$1980-1986$} \\
\hline & $\mathrm{kg} \mathrm{N}$ & $(\%)$ & $\mathrm{kg} \mathrm{N}$ & $(\%)$ & $\operatorname{kg~N}$ & $(\%)$ \\
\hline Fish food & 2160 & (95) & 1200 & $(93)$ & 12780 & (94) \\
\hline Juveniles & 110 & (5) & 90 & (7) & 800 & (6) \\
\hline Harvest & 610 & $(27)$ & 360 & $(28)$ & 3710 & $(27)$ \\
\hline Fish loss & 40 & (2) & 60 & (5) & 350 & (3) \\
\hline Solute release & 1100 & $(48)$ & a & & & \\
\hline Sedimentation & 520 & (23) & a & & & \\
\hline Benthic net flux & 60 & (3) & 20 & (1) & & \\
\hline $\mathrm{DON}^{\mathrm{b}}$ & 56.8 & $(10.9)$ & 9.2 & $a, b$ & & \\
\hline Ammonium ${ }^{b}$ & 1.9 & (0.4) & 8.8 & $a, b$ & & \\
\hline Nitrate $^{\mathrm{b}}$ & 0.8 & $(0.2)$ & 0.6 & d, b & & \\
\hline Urea $^{\mathrm{b}}$ & 0.2 & $(0.04)$ & 0 & & & \\
\hline Denitrification $^{\mathrm{b}}$ & $5 \times 10^{-2}$ & $(0.01)$ & $2 \times 10^{-3}$ & $a, b$ & & \\
\hline Sediment accumulation & 460 & $(20)$ & a & & 1600 & $(12)$ \\
\hline Total environmental loss & 1620 & $(71)$ & 870 & $(67)$ & 9520 & $(70)$ \\
\hline Dissolved environmental loss & 1160 & (51) & a & & 7920 & (58) \\
\hline
\end{tabular}

seasonal basis constitute an alternative approach to estimating degradation rates, and how fast different elements degrade in relation to each other, in farmderived sediments.

DON fluxes, followed by ammonium fluxes, made the largest contribution to the seasonal benthic flux during both 1985 and 1986 (Fig. 6B, Table 4). Nitrate was always taken up by the sediment. Very few previous measurements of benthic nitrogen fluxes in fish cage farms have been reported. Knowledge of the composition and direction of nitrogen fluxes into or out of farm sediments is needed for development of models on eutrophication effects (Aure \& Stigebrandt 1990, Wallin \& Håkanson 1990). Denitrification, the rate of which was much lower than the nitrate flux into the sediment, made a very minor contribution to the transfer of nitrogen from the farm sediment to the water column. Most of the nitrate taken up by the sediment must have been reduced dissimilatorily to ammonium, or reduced by sulfide. Low denitrification rates have also been measured in other cage farm sediments (Kaspar et al. 1988) and in sediments of fish ponds (Blackburn et al. 1988).

\section{Possible sources of error in the mass balances}

Processes other than those taken into account in the mass balances may possibly add or remove nitrogen from the farm or the underlying sediment (examples shown in Fig. 6A). Such processes were discussed in
Hall et al. (1990) and Holby \& Hall (1991). Of those, the most serious one probably is resuspension. However, the order of magnitude of error caused by resuspension may be estimated from comparisons of the mass balances (see above).

A high-temperature catalytic oxidation (HTCO) method for determining total dissolved nitrogen and DON in seawater has been reported to give considerably higher values than traditional wet oxidation methods (Suzuki et al. 1985), one of which was utilized in this study. If the discrepancy between methods is also applicable to our samples, and if the higher values obtained with the HTCO-method are not to a large extent a result of uncorrected high blanks [which has been suggested to be a major reason for high HTCO-values for dissolved organic carbon (Williams 1991)], then the DON-fluxes reported here may be underestimated.

It has been reported that hydrogen sulfide can interfere with the acetylene inhibition technique to measure denitrification (Sørensen et al. 1980). If this was the case in the farm sediment, our denitrification measurements are underestimates. However, we believe that the very low denitrification rates measured here are low neither as a result of sulfide interference on the acetylene inhibition method, nor because acetylene may have inhibited nitrification forming nitrate for denitrification (Walter et al. 1979), but because of the very organic-rich and reduced conditions (Tiedje et al. 1982) and the low availability of nitrate for denitrification. 


\section{Environmental implications}

This study has quantified the nitrogen load to the environment and the composition of this load, and contributes an assessment of the environmental impact with regard to eutrophication caused by a marine fish cage farm. Most of the nitrogen lost to the environment (72 to $83 \%$, including the contribution from the sediment) was in dissolved form, possibly having a direct stimulatory effect on primary production, especially in coastal areas that are often nitrogen limited. However, the exact eutrophication effects cannot be clarified from the present study, but have to be investigated separately, e.g. by studying algal growth on glass surfaces placed in the water at different distances from the farm (Persson 1986).

The nitrogen sedimentation rate $200 \mathrm{~m}$ outside the farm was 10 times lower than the mean annual sedimentation rate of nitrogen below the cages. The surface sediment below the cages was 10 to 15 times enriched with nitrogen compared to the sediment $20 \mathrm{~m}$ outside the farm. Also the pore water ammonium level was drastically enhanced below the cages compared to the pore water of the sediment $20 \mathrm{~m}$ outside the farm. These observations indicate that the influence of the farm on the environment with regard to particle dispersion is rather limited in space, but that the bottom below the farm is heavily influenced by particle deposition from the cages.

The ammonium fluxes from the farm sediment were significantly higher during anoxic conditions than when the overlying water was oxygenated. This shows the importance of selecting well-flushed farm sites, so that a good oxygen status of the bottom water is maintained and possible enhanced eutrophication prevented.

\section{Interelemental relationships in the farm: the fate of C, P, Si and N}

The fate and removal pathways of carbon, phosphorus and silicon supplied to the farm were described in other papers in this series (Hall et al. 1990, Holby \& Hall 1991, unpubl.). Below, a comparison of these elements and nitrogen in the farm is made.

Almost all of the carbon (94 to $96 \%$ ), phosphorus $(94$ to $97 \%$ ) and nitrogen ( 93 to $95 \%$ ) input to the farm was supplied with fish food. The rest was supplied with juvenile fish. Harvest removed 21 to $22 \%$ of the C, 17 to $19 \%$ of the P, and 27 to $28 \%$ of the $\mathrm{N}$ input to the farm. The harvest results, as well as the losses to the environment found (see below), suggest that the fish more efficiently took up the $N$ than the $C$ and $P$ supplied with food. Fish loss (death and escape) removed a small fraction of the $\mathrm{C}(1$ to $3 \%), \mathrm{P}(1$ to $4 \%)$ and $\mathrm{N}$ ( 2 to $5 \%$ ) input to the farm. Most of the C (75 to $78 \%$ ), $\mathrm{P}(78$ to $82 \%)$ and $\mathrm{N}(67$ to $71 \%)$ supplied to the cages was lost to the environment. The environmental loss amounted to 878 to $952 \mathrm{~kg} \mathrm{C} \mathrm{t}^{-1}, 20$ to $22 \mathrm{~kg} \mathrm{P} \mathrm{t}^{-1}$, and 95 to $102 \mathrm{~kg} \mathrm{~N} \mathrm{t}^{-1}$ of fish produced. There was a discrepancy between elements with regard to the composition of this loss. The dissolved fraction dominated for both $C$ and $N$ constituting 71 to $76 \%$ and 72 to $83 \%$ of the total loss, respectively. For $\mathrm{P}$ the particulate fraction dominated and constituted 59 to $66 \%$ of the total loss. Release of solutes directly from the fish (e.g. carbon dioxide, urea, ammonia) contributed much more to the dissolved environmental loss for all 3 elements than did solute fluxes from the sediment below the farm. Dissolved inorganic carbon (total carbon dioxide), phosphate and DON were the quantitatively most important $\mathrm{C}$-, $\mathrm{P}$ - and $\mathrm{N}$-solutes released from the farm sediment on a seasonal basis. Annually benthic solute lluxes removed 1 to $5 \%$ of the $\mathrm{C}$, a little less than $1 \%$ of the $\mathrm{P}$, and 1 to $4 \%$ of the $\mathrm{N}$ content of the farmderived sediment, which suggest that $\mathrm{C}$ and $\mathrm{N}$ were degraded faster than $\mathrm{P}$ in the farm sediment.

Sources and sinks for silicon in the farm were significantly different than for the other 3 elements. Almost all (about $99.7 \%$ ) of the Si supplied to the farm with fish food was lost to the environment, and hence a very small fraction was taken up by the fish. The environmental loss amounted to 2.4 to $2.5 \mathrm{~kg} \mathrm{Si} \mathrm{t}^{-1}$ of fish produced. The dominating part of the particulate Si caught in sediment traps below the cages did not originate from fish food, but must have come externally to the farm. The net long-term accumulation of Si in the farm sediment could also only to a small extent (ca $20 \%$ ) be explained by the transfer of fish food Si to sediment. Most of the Si in the sediment is suggested to have been brought there by the farm creating. through the release of nitrogen and phosphorus to the water, a favourable niche for diatoms and other silicon utilizing organisms, and thereby increasing the flux of biogenic silica to sediment. This is the rationale for the so called 'external input' of Si to the farm. Annually the benthic dissolved silicate flux transfered $0.3 \%$ of the biogenic silica present in the farm sediment to the overlying water

Acknowledifements. We thank personnel at the Kristineberg Marine Binlogical Station for hospitality and support and especially $\mathrm{O}$. Lindahl for providing sediment traps and for valuable methodology discussions; S. Sanzgiry and P Áberg for assistance during field work; G. Persson for valuable discussions; 3 anonymous referees for critical comments on an early version of the manuscript; and the Swedish Environmental Research institute (IVL) for support to M.O.S. This study was supported financially by the National Swedish Environmental Protection Agency (SNV). 


\section{LITERATURE CITED}

Ackefors, H. (1986). The impact on the environment by cage farming in open water. J. Aqua. Trop. 1: 25-33

Ackefors, H., Enell, M. (1990). Discharge of nutrients from Swedish fish farming to adjacent sea areas. Ambıo 19: $28-35$

Anderson, L. (1979). Simultaneous spectrophotometric determination of nitrite and nitrate by flow injection analysıs. Anal. Chim. Acta 110: 123-128

Aure, J., Stigebrandt, A. (1990). Quantitative estimates of the eutrophication effects of fish farming on fjords. Aquaculture 90: 135-156

Blackburn, T. H., Lund, B. A.a., Krom, M. D. (1988). C- and Nmineralization in the sediments of earthen marine fishponds. Mar. Ecol. Prog. Ser. 44: 221-227

Enell, M. (1987). Environmental impact of cage fish farming with special reference to phosphorus and nitrogen loadings. Comm. Meet. int. Coun. Explor. Sea, C.M.-ICES/F: 44. Ref. MEQC

Folke, C., Kautsky, N. (1989). The role of ecosystems for a sustainable development of aquaculture. Ambio 18: 234-243

Gowen, R. J., Bradbury, N. B. (1987). The ecological impact of salmonid farming in coastal waters: a review. Oceanogr. mar. Biol. A. Rev. 25: 563-575

Gowen, R. J., Bradbury, N. B., Brown, J R. (1985). The ecological impact of salmon farming in Scottish coastal waters: a preliminary appraisal. Comm. Meet. int. Coun. Explor. Sea, C.M.-ICES/F: 35, Ref. E+C, Sess. W

Håkanson, L., Ervik, A., Mäkinen, T., Möller, B. (1988). Basic concepts concerning assessments of environmental effects of marine fish farms. Report Nord 1988:90. Nordic Council of Ministers, Copenhagen

Hall, P. O. J. (1984). Chemical fluxes at the sedimentseawater interface; in-situ investigations with benthic chambers. Ph.D. thesis, Univ. of Göteborg

Hall, P. O. J., Anderson, L. G., Holby, O., Kollberg, S., Samuelsson, M.-O. (1990). Chemical fluxes and mass balances in a marine fish cage farm. I. Carbon. Mar. Ecol. Prog. Ser. 61: 61-73

Holby, O., Hall, P. O.J. (1991). Chemical fluxes and mass balances in a marine fish cage farm. II. Phosphorus. Mar. Ecol. Prog. Ser. 70: 263-272

Kaspar, H. F., Hall, G. H., Holland, A. J. (1988). Effects of sea cage salmon farming on sediment nitrification and dissimilatory nitrate reductions. Aquaculture 70: 333-344

Molvoer, J., Stigebrandt, A. (1989). Om utskillelse av fosfor og nitrogen fra fiskeoppdrettsanlegg. Report 2262. Norweg. Inst. Wat. Res., Oslo

Newell, B. S., Morgan, B., Cundy, J. (1967). The determination of urea in seawater. J. mar. Res. 25: 201-202

Penczak, T., Galicka, W., Molinski, M., Kusto, E., Zalewski, M. (1982). The enrichment of a mesotrophic lake by carbon, phosphorus and nitrogen from the cage aquaculture of rainbow trout, Salmo gairdneri. J appl. Ecol. 19: $371-393$

This article was submitted to the editor
Persson, G. (1986). Kassodling av regnbäge; Närsaltemissioner och miljö vid tre odlingslägen längs Smålandskusten. Report 3215. National Swedish Environmental Protection Board, Solna

Persson, G. (1987). Sambandet mellan foda, produktion och förorening vid odling av stor regnbáge (Salmo gardneri). Report 3382. National Swedish Environmental Protection Board, Solna

Phillips, M. J., Beveridge, M. C. M., Muir, J. F. (1985). Waste output and environmental effects of rainbow trout cage culture. Comm. Meet. int. Coun. Explor. Sea, C.M.ICES/F: 21, Maricult Comm., Sess. W

Rönner, U. (1.983). Biological nitrogen transformations in marine ecosystems with emphasis on denitrification. Ph.D. thesis, Univ, of Göteborg

Rosenthal, H., Weston, D., Gowen, R., Black, E. (eds.) (1988). Report of the ad hoc study group on Environmental Impact of Mariculture. ICES Coop. Res. Rep. 154

Samuelsson, M.-O. (1986). Dissimilatory nitrate reduction in the marine environment. Ph.D. thesis, Univ. of Göteborg

Santschi, P., Höhener, P., Benoit, G., Buchholtz-ten Brink, M. (1990). Chemical processes at the sediment-water interface. Mar. Chem. 30: 269-315

Solorzano, L. (1969). Determination of ammonia in natural waters by the phenolhypochlorite method. Limnol. Oceanogr. 14: 799-801

Sorensen, J. (1978a). Denitrification rates in a marine sediment as measured by the acetylene inhibition technique. Appl. environ. Microbiol. 36: 139-143

Sorensen, J (1978b). Capacity for denitrification and reduction of nitrate to ammonia in a coastal marine sediment. Appl. environ. Microbiol. 35: 301-305

Sorensen, J., Tiedje, J. M., Firestone, R. B. (1980). Inhibition by sulfide of nitric and nitrous oxide reduction by denitrifying Pseudomonas fluorescens. Appl, environ Microbiol. 39: $105-108$

Suzuki, Y., Sugimura, Y., Itoh, T (1985). A catalytic oxidation method for the determination of total nitrogen dissolved in seawater. Mar. Chem. 16:83-97

Tiedje, J. M., Sexstone, A. J., Myrold, D. D., Robinson, J. A. (1982). Denitrification: ecological niches, competition and survival. Antonie van Leeuwenhoek J. Microbiol. Serol. 48: $569-583$

Valderrama, J. C. (1981). The simultaneous analysis of total nitrogen and total phosphorus in natural waters. Mar. Chem. 10: 109-122

Wallin, M., Håkanson, L. (1990). Nutrient loading models for the assessment of environmental effects of marine fish farms. Vatten 46: $224-236$

Walter, H. M., Keeney, D. R., Fillery, 1. R. (1979). Inhibition of nitrification by acetylene. Soil Sci. Soc. Amer. J. 43: 195-196

Williams, P. M. (1991). Scientists and industry reps attend workshop on measuring DOC and DON in natural waters. U.S. JGOFS News 3(1): 1-11

Manuscript first received: February 27, 1992

Revised version accepted: October 14, 1992 